\title{
Extensive Posterolateral Approach for Giant Spinal Epidural Tumors
}

\author{
Janez Ravnik ${ }^{1}$, Jan Štangelj ${ }^{1}$, Jaka Košar ${ }^{2}$ \\ ${ }^{1}$ Department of Neurosurgery, University Medical Centre Maribor, ${ }^{2}$ Department of Traumatology, University Medical Centre \\ Maribor \\ Correspondence: janez.ravnik@ukc-mb.si; Tel.: + 3862321 1724: Fax.: + 38623314531
}

Received: 28 April 2020; Accepted: 13 November 2020

\begin{abstract}
Objective. Our objective was to determine the safety, efficacy, and surgical outcome of an extensive posterolateral approach for giant spinal epidural tumors. Materials and Methods. Our clinical study included 12 patients with various giant primary tumors and metastases of the spine, who underwent surgery between 2008 and 2019. The surgical procedure consisted of costotransversectomy, laminectomy, corpectomy, tumor resection, spinal column stabilization, and reconstruction. Neurological status examination and pain assessment were recorded at the time of admission, upon discharge and at outpatient check-up. Results. In our clinical sample, there were no major perioperative complications. All patients were discharged from the intensive care unit back to the hospital department within a week after the surgery. Postoperative follow-up showed no deterioration of neurological status. Furthermore, there was a moderate to significant improvement of paraparesis in all patients for weeks after surgery. The most notable improvement was significant pain relief in all the patients. None of the patients had issues with failure of the implanted hardware. Two patients died less than six months after the surgery due to the progression of the primary malignant process. Conclusion. An extensive posterolateral approach to giant spinal epidural tumors is an effective one-step approach. It presents a good compromise between invasiveness and sufficient exposure for both tumor resection and spinal column reconstruction. Good short-term clinical improvement can be achieved, but the long term results depend on the advancement of the initial disease. Careful evaluation and selection of patients are necessary to achieve clinical improvement and prolonged life expectancy, and the best results are achieved with a multidisciplinary approach.
\end{abstract}

Key Words: Spinal Epidural Tumor - Neurosurgical Procedure - Posterolateral Approach • Complete Tumor Resection - Stabilization.

\section{Introduction}

Modern oncological treatment has resulted in the prolonged life expectancy of patients with spinal tumors, both primary and metastatic. Past studies have shown the presence of spinal metastases in $36.1 \%$ of patients dying from a neoplastic disease, whereas more recent studies have shown that this percentage has increased (1). Symptoms of epidural spinal tumors arise from spinal cord compression (SCC), and manifest most commonly as worsening pain, usually present eight weeks before the diagnosis, in up to $95 \%$ of patients. Common symptoms include motor deficit, manifesting as a weakness at the time of diagnosis (60-85\%). Senso- ry deficits are subjectively less evident in comparison with motor deficits, but can still be detected in $40-90 \%$ patients with a thorough neurological examination. Sphincter dysfunctions can present in later stages of SCC, in concordance with motor deficits (2-4). Unfavorable clinical presentations of epidural spinal tumors, and the consequent severe impact on the quality of life (QoL), create increasing demand for medical treatment. Surgical interventions of various extents can significantly improve QoL and remain irreplaceable in the modern approach to spinal tumors (2-5). Several other studies have addressed posterior or posterolateral approaches for tumors of the thoracic spine. Relevant studies are presented in Table 1. 
Table 1. Studies which have Addressed Posterior or Posterolateral Approaches for Tumors of the Thoracic Spine

\begin{tabular}{|c|c|c|c|}
\hline Authors & Sample & Methods & Results and complications \\
\hline Rong et al. (6) & $\begin{array}{l}14 \text { patients with dumbbell } \\
\text { tumors involving up to two } \\
\text { segments of the thoracic } \\
\text { spine. }\end{array}$ & $\begin{array}{l}\text { Posterolateral approach with unilateral } \\
\text { laminectomy, decompression, } \\
\text { costotransversectomy. No } \\
\text { instrumentation. }\end{array}$ & $\begin{array}{l}\text { Gross total removal of tumor in } 13 \\
\text { patients, no significant operative or } \\
\text { postoperative complications occurred in } \\
\text { any patient. }\end{array}$ \\
\hline Gezercan et al. (8) & $\begin{array}{l}22 \text { patients with tumors of } \\
\text { either thoracic or lumbar } \\
\text { spine. }\end{array}$ & $\begin{array}{l}\text { Posterolateral approach with either } \\
\text { unilateral or bilateral decompression, } \\
\text { posterior stabilization and anterior } \\
\text { reconstruction. }\end{array}$ & $\begin{array}{l}\text { No complications in } 14 \text { patients }(63.64 \%) \text {, } \\
4 \text { patients }(18.18 \%) \text { died within } 20 \\
\text { months, neurological deficit in one } \\
\text { patient }(4.54 \%) \text {, failure in instrumentation } \\
\text { in } 2 \text { patients }(9.09 \%) \text {. }\end{array}$ \\
\hline $\begin{array}{l}\text { Rustagi, Mashaly, } \\
\text { Ganguly, Ahkter, } \\
\text { Mendel (9) }\end{array}$ & $\begin{array}{l}96 \text { patients with tumors } \\
\text { of the thoracic spine. } 73 \\
\text { patients }(76 \%) \text { had single } \\
\text { level involvement. }\end{array}$ & $\begin{array}{l}\text { Posterior approach, wide laminectomy, } \\
\text { decompression, transpedicular } \\
\text { stabilization, vertebrectomy, anterior } \\
\text { reconstruction. } 18 \text { patients (18.25\%) } \\
\text { had anterior reconstruction with } \\
\text { titanium cage. }\end{array}$ & $\begin{array}{l}18.75 \% \text { of patients had neurological } \\
\text { improvement. } 2.08 \% \text { of patients had } \\
\text { neurological deterioration. } \\
29.16 \% \text { of patients had surgical } \\
\text { complications, } 11.4 \% \text { of patients had } \\
\text { major postoperative complications. } 4 \% \text { of } \\
\text { patients died within one month. }\end{array}$ \\
\hline Wang et al. (10) & $\begin{array}{l}140 \text { patients with various } \\
\text { metastases in the thoracic } \\
\text { spine. }\end{array}$ & $\begin{array}{l}\text { Posterolateral approach, wide } \\
\text { laminectomy, decompression, } \\
\text { transpedicular stabilization, and } \\
\text { vertebrectomy - one segment in } 104 \\
\text { pateints }(74 \%) \text {, two segment in } 27 \\
\text { patients }(19 \%) \text { and three segment } \\
\text { in } 4 \text { patients }(2.9 \%) \text { and anterior } \\
\text { reconstruction. }\end{array}$ & $\begin{array}{l}134 \text { patients ( } 94 \%) \text { had significant pain } \\
\text { improvement. Overall median survival } \\
\text { was } 7.7 \text { months. } 20 \text { patients ( } 14.3 \%) \text { had } \\
\text { major postoperative complications, } 6 \\
\text { patients }(3.7 \%) \text { died within } 30 \text { days. } 7 \\
\text { patients }(5 \%) \text { had instrumentation failure. }\end{array}$ \\
\hline Joubert et al. (11) & $\begin{array}{l}34 \text { patients with spinal } \\
\text { metastases }-30 \text { in the } \\
\text { thoracic spine and } 4 \text { in the } \\
\text { lumbar spine. }\end{array}$ & $\begin{array}{l}\text { Posterior or posterolateral approach, } \\
\text { wide laminectomy, decompression, } \\
\text { transpedicular stabilization, unilateral } \\
\text { costotransversectomy, anterior } \\
\text { reconstruction. }\end{array}$ & $\begin{array}{l}\text { Neurological improvement in } 23 \\
\text { patients }(67.6 \%) \text {, no neurological } \\
\text { deterioration. Median overall survival } \\
\text { was } 13.7 \text { months. One patient had major } \\
\text { postoperative complication. No failure of } \\
\text { instrumentation was observed. }\end{array}$ \\
\hline
\end{tabular}

Despite the relative abundance of results, there is little uniformity among studies in terms of patient selection, their condition, the size of the tumor, and surgical technique. Therefore direct comparison between the studies listed is not a viable option.

Our clinical study analyzed the surgical treatment of primary or metastatic thoracic spinal tumors involving the anterior or posterior column. It challenged the otherwise well-proven and effective transthoracic anterior, posterior, or a combined approach as the surgical approach of choice. A giant spinal epidural tumor is defined as a spinal epidural lesion that extends over two or more vertebral levels.

The aim of our study was to determine the safety, efficacy, and surgical outcome of the extensive posterolateral approach for giant spinal epidural tumors. The data obtained can be used for better preoperative planning, and improving the treatment strategy as a whole.

\section{Methods}

\section{Patients}

In our clinical study we included 12 patients with giant spinal epidural tumors, who underwent surgery during the period between 2008 and 2019. There were five male and seven female patients, with a mean age of 51 years, ranging from 16 to 70 years. Eight patients had various multilevel spinal metastases. In all eight patients the metastases were large, extensively vascularized, and in direct proximity to the dura, a lung, the aorta, vena cava, or a combination of the above. Two patients had been diagnosed with chondrosarcoma, one patient with synovial sarcoma, and one patient with an an- 
Acta Medica Academica 2020;49(Suppl 1):S30-36

Table 2. Patients with Giant Spinal Epidural Tumors, who Underwent Surgery during the Period between 2008 and 2019

\begin{tabular}{llll}
\hline Age (yrs) & Gender & Tumor type & Remarks \\
\hline 16 & Male & Aneurismatic bone cyst Th 7-9 & Complete removal, fast recovery. \\
\hline 34 & Male & Synovial sarcoma Th 3-4 & - \\
\hline 40 & Female & Metastasis of breast carcinoma Th 3-5 & Death within 6 months. \\
\hline 47 & Male & Chondrosarcoma Th 5-7 & Complete removal with dissection of the tumor. \\
\hline 50 & Male & Metastasis of mixed testicular carcinoma Th 3-5 & $\begin{array}{l}\text { Complete removal, single metastasis, in remission without } \\
\text { neurological impairment. }\end{array}$ \\
\hline 51 & Male & Diffuse spinal plasmocytoma C6-Th1 & - \\
\hline 56 & Female & Metastasis of kidney clear cell carcinoma Th 6-8 & Significant blood loss, long postoperative recovery. \\
\hline 61 & Female & Metastasis of colorectal carcinoma Th 5-6 & - \\
\hline 62 & Female & Chondrosarcoma Th 6-7 & »En bloc« resection achievable. \\
\hline 63 & Female & Metastasis of malignant melanoma Th 9-10 & Death within 6 months. \\
\hline 66 & Female & Metastasis of lung carcinoma Th 6-7 & Long postoperative recovery. \\
\hline 70 & Female & Metastasis of breast carcinoma Th 5-6 & - \\
\hline
\end{tabular}

eurismatic bone cyst. In all patients with primary tumors they were formed in a dumb-bell shape. The patients are presented in Table 2.

At the time of admission, neurological status examination in all patients revealed progressive paraparesis and prominent pain to various degrees. Pain was assessed using the Visual Analogue Scale (VAS). All patients had a generally good performance index, and underwent imaging diagnostics (magnetic resonance imaging - MRI and computer tomography - CT).

Examples of the preoperative MRIs of selected patients are presented in Figure 1 and Figure 2.

All patients underwent surgery using the onestep posterolateral approach. The main goal for the

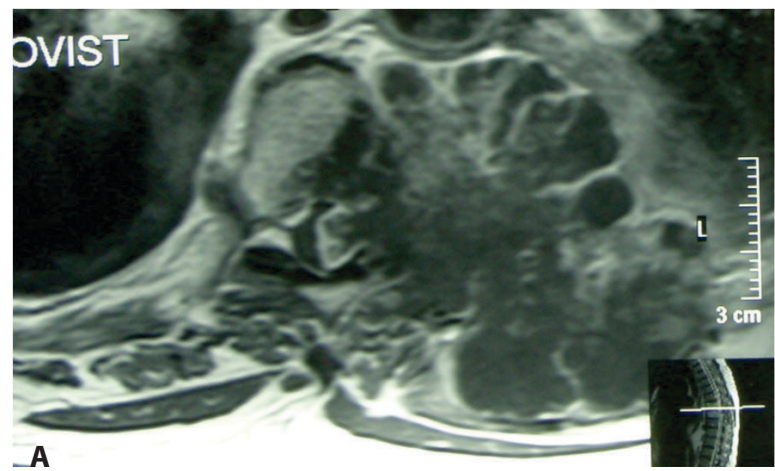

Figure 1. Preoperative MRI of a Patient with Chondrosarcoma of $6^{\text {th }}$ and $7^{\text {th }}$ Segments of the Thoracic Spine. A: Axial View. B: Coronal View. operative outcome in patients with metastases was radical tumor resection, and total tumor resection in patients with primary tumors.

\section{Surgical Technique}

A multidisciplinary approach was necessary, so surgeries were performed in tandem with a neurosurgeon and a trauma surgeon. After induc-

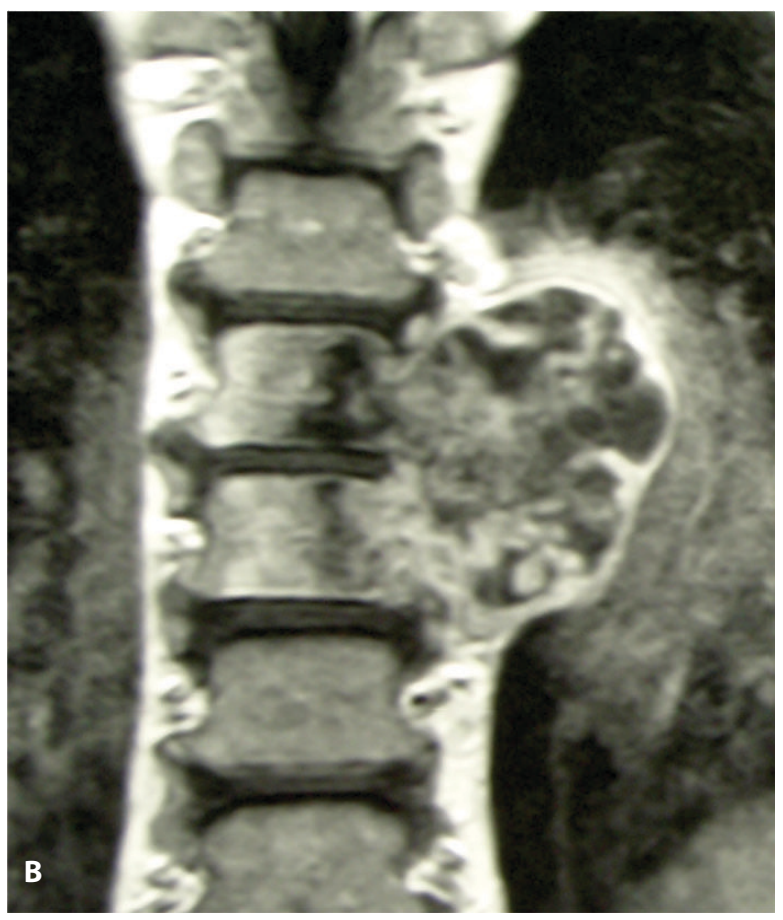




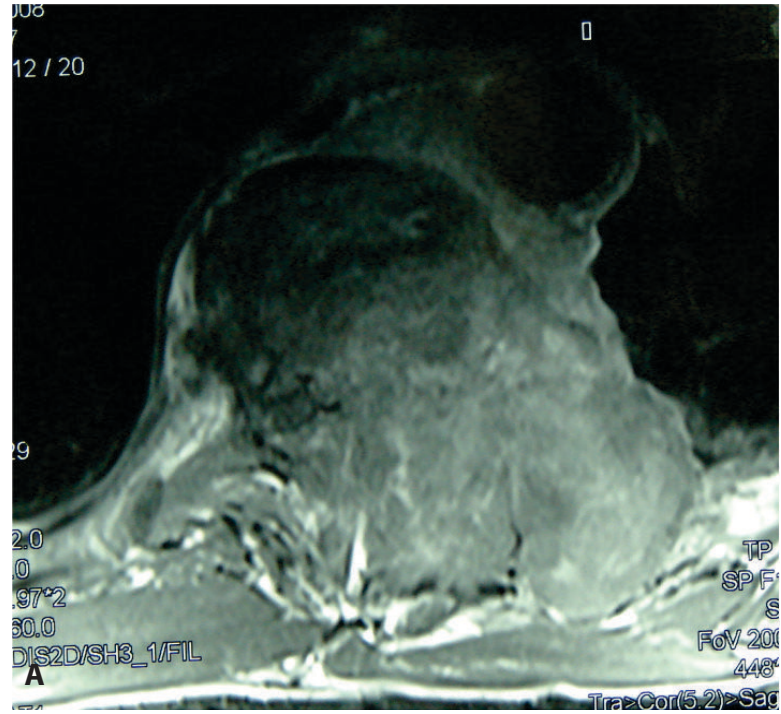

Figure 2. Preoperative MRI of a Patient with Metastasis of a Colorectal Carcinoma of the $5^{\text {th }}$ and $6^{\text {th }}$ Segments of the Thoracic Spine. A: Axial View. B: Sagittal View.

tion of anesthesia, all patients were turned into the prone position. An extended midline incision was made, and the paravertebral muscles were detached from the spinous processes to expose the affected vertebras. To obtain sufficient exposure, muscle detachment of at least 2-3 neighboring segments in caudal and cranial directions was necessary. Laminectomy and total gross resection of the tumorous posterior column were performed, followed by bilateral costotransversectomy on all the affected vertebras so that the pleura was sufficiently exposed and free of the tumor. Subsequent corpectomy was performed - total in six patients, and partial in six patients. Leksell, Kerrison, and Ferris-Smith rongeurs were used in this process. Hemostasis at this point was challenging, and we used a bipolar coagulator and various haemostatic materials. Next, discectomy of neighboring segments was performed. In 11 patients, a titanium cage of appropriate size was inserted to reconstruct the anterior column. In one patient, we used a temporary polymethyl methacrylate interbody spacer. In this patient, we later performed another operation using a transthoracic approach for removal of the polymethyl-methacrylate interbody spacer, followed by anterior interbody fusion with

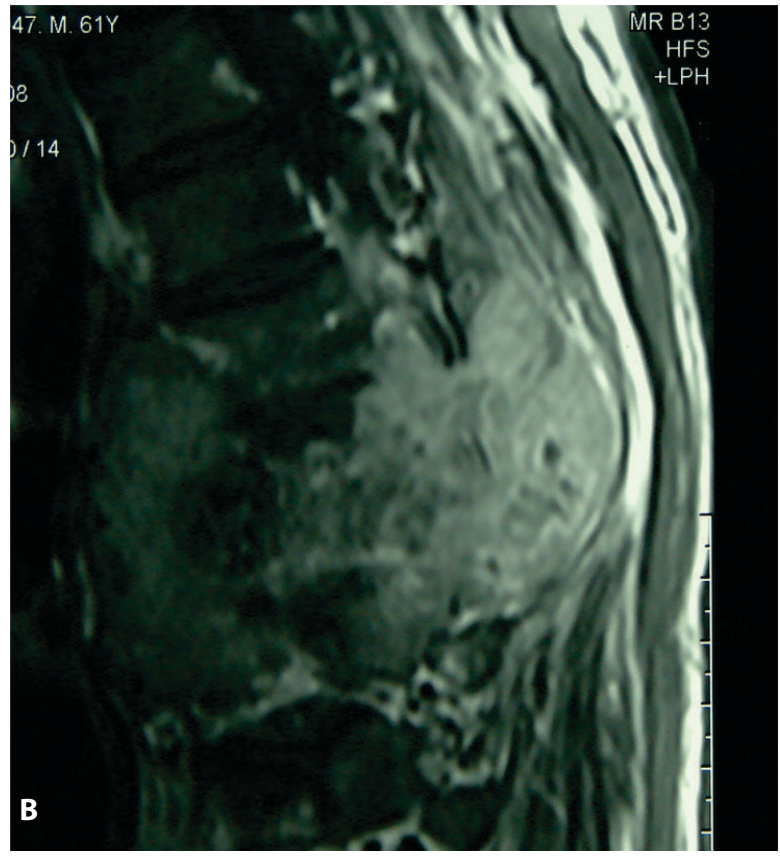

an iliac crest tricortical graft, and an anterior plate fixation system.

At the stage when discrete manipulation of the dura and spinal cord was necessary, neuromonitoring was used to control the deterioration of motoric and somatosensoric evoked potentials. Neuromonitoring allowed us to adjust the technique of resection or titanium cage insertion promptly, when harmful manipulation of the dura and spinal cord was registered, thus avoiding any long-term iatrogenic neurological deterioration. In all patients, posterior column stabilization was necessary. We used Universal Spinal System (USS) screws, and a rod fixation system on 2-3 neighboring segments in the cranial and caudal direction.

Neurological status examination and pain assessment were repeated upon discharge and at outpatient check-ups approx. 3 weeks after discharge. All the procedures used in our study were in accordance with the Declaration of Helsinki from 1975 and its amendments from 1983.

\section{Results}

Our results showed that costotransversectomy, laminectomy, corpectomy, spinal column stabili- 
zation, and reconstruction via an extensive posterolateral approach were successful in the treatment of giant spinal epidural metastases and primary tumors.

Examples of spinal stabilization and fixation with USS, as performed in all the patients, are presented in Figure 3, Figure 4 and Figure 5.

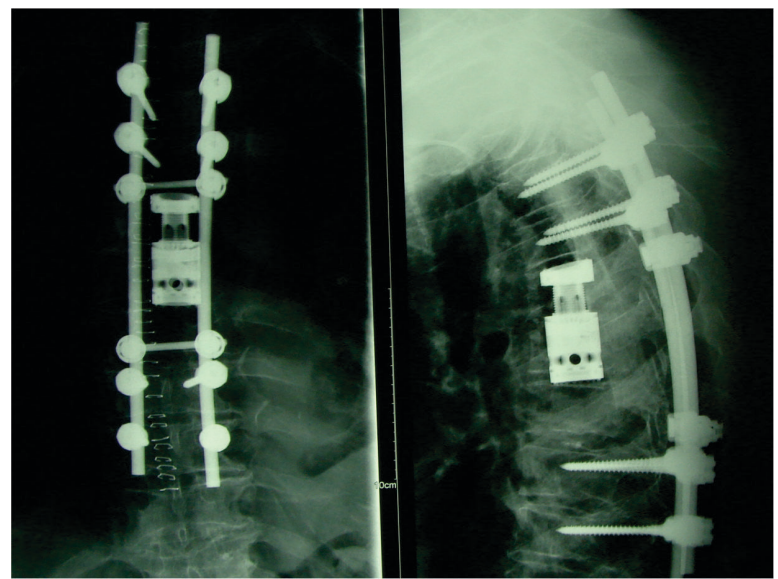

Figure 3. Postoperative CT of a Patient after Vertebrectomy of the $5^{\text {th }}$ and $6^{\text {th }}$ Segments of the Thoracic Spine, Cage Insert and Fixation with the Universal Spine System between the $2 \mathrm{nd}$ and $\mathrm{9}^{\text {th }}$ Segments of the Thoracic Spine (coronal and Sagittal View).

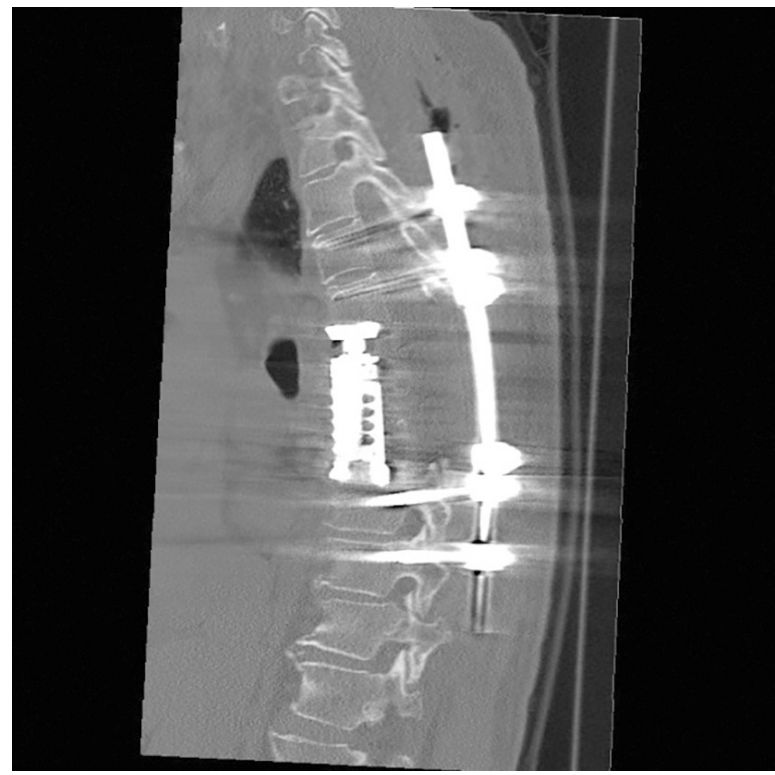

Figure 4. Postoperative CT, Sagittal View, of a Patient after Vertebrectomy of the $6^{\text {th }}, 7^{\text {th }}$ and $8^{\text {th }}$ Segments of the Thoracic Spine, Cage Insertion and Fixation with the Universal Spine System between the $4^{\text {th }}$ and $10^{\text {th }}$ Segments of the Thoracic Spine.

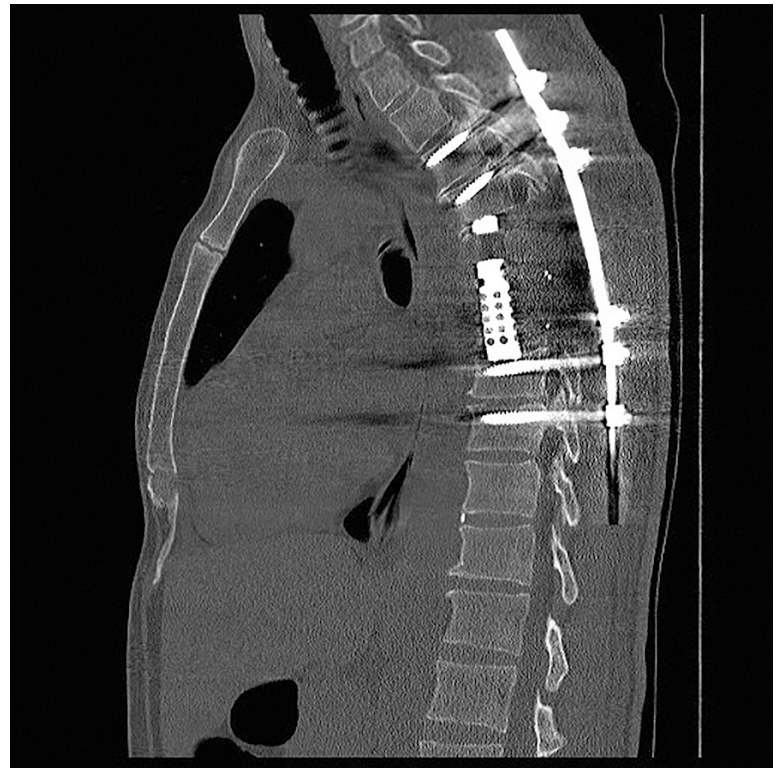

Figure 5. Postoperative CT, Sagittal View, of a Patient after Vertebrectomy of the $5^{\text {th }}, 6^{\text {th }}$ and $7^{\text {th }}$ Segments of the Thoracic Spine, Cage Insertion and Fixation with the Universal Spine System between the $3^{\text {rd }}$ and $9^{\text {th }}$ Segments of the Thoracic Spine.

Despite the extended duration of the operation and significant blood loss during tumor resection and vertebrectomy, there were no major perioperative complications. All patients were discharged from the intensive care unit back to the hospital department within a week after the surgery.

Postoperative follow-up showed no deterioration of neurological status. Furthermore, there was a moderate to significant improvement of paraparesis in all patients for weeks after surgery. The most notable improvement was significant pain relief in all of the patients. None of the patients had issues with failure of the implanted hardware. Two patients died less than six months after the surgery due to the advancement of the primary malignant process.

\section{Discussion}

In the present study we demonstrated the suitability of an extensive posterolateral approach in cases of giant spinal epidural metastases and primary tumors such as chondrosarcomas, synovial sarcomas and aneurismatic bone cysts. 
Using the extensive posterolateral approach enabled us to achieve maximal tumor resection and spine instrumentation in a one-step procedure. Similar results were achieved in other recent clinical studies that addressed the posterolateral approach (6-12). Despite its relative invasiveness, we confirmed that such an approach is safe and predictable as it is more familiar to neurosurgeons than the transthoracic approach, that usually requires the assistance of thoracic surgeons as well. Surgical treatment of patients with cervical spine tumors favors the extensive posterolateral approach even more as it facilitates septation of the vertebral artery, and enables complete exposure of lateral portions of dumb-bell tumors similar to those in other segments of the spine. In their clinical study, Zhao et al. achieved complete resection of the tumor with insignificant blood loss (13).

The selection of patients for operative treatment was challenging since no scoring system can reliably evaluate every patient with a spinal tumor. Our selection process focused on predicting patients' QoL and life expectancy. The decision-making process is usually multidisciplinary, and the NOMS, Tomita, Tokuhashi, and Karnofsky scales have to be taken into consideration.

Despite favourable results in the early postoperative phase in our study, there was susceptibility for general complications for patients with spinal metastases, which is in line with the study by Choi et al. (14). Due to the anatomical challenges in spine surgery, severe complications, such as injury to neural structures, the lungs, or vascular and visceral injuries, might occur. Mohme et al. and Bellut et al. showed better postoperative pain improvement in patients with a higher degree of stenosis, and those with an associated degenerative condition of the spine (15, 16). The histological type of the tumor does not predict early postoperative outcome but has an impact on prognosis. The anatomical location of the tumor affects the postoperative outcome. In essence, patients with SCC in the cervical spine benefited from surgical treatment the most; patients with SCC in the thoracic spine had less favourable prognostic factors in terms of postoperative pain, while patients with primary tumors in the sacral region had less favourable overall survival (15).

In our study, no patient required revision. In the study by Quraishi et al., reoperation rates of spinal metastases remained relatively low (10.7\%), with surgical site infection accounting for $42 \%$, failure of instrumentation $26 \%$, and local recurrence $16 \%$ of revisions (17). The difference between our study and Quraishi et al. is a result of the smaller number of cases.

In general, surgical treatment should be offered to selected patients with primary spine tumors or spinal metastases, as it provides rapid improvement in pain, and to a certain extent, improved neurological performance. Indications for surgery are wide, since even less extensive palliative procedures significantly improve QoL. Postoperative follow-up in similar clinical studies showed improvement or at least stabilization of the patients' symptoms, with very few patients deteriorating in the months following the surgery. Age $>80$ years contributes to less neurological improvement after surgery; however, age itself should not be the determinative factor in the decision for surgical treatment. Functional outcome and QoL can be significantly improved despite a short survival rate (18).

\section{Conclusion}

In our study, we showed the suitability of an extensive posterolateral approach with costotransversectomy, laminectomy, corpectomy, spinal column stabilization, and reconstruction as a safe and effective one-step approach. It represents a good compromise between invasiveness and sufficient exposure for both tumor resection and spinal column reconstruction, for selected patients with extradural tumors with spinal canal involvement.

Good short-term clinical improvement can be achieved, but the long term results depend on the advancement of the initial disease. Careful evaluation and selection of patients are necessary to achieve clinical improvement and prolonged life expectancy. The best results are achieved with a multidisciplinary approach. 


\section{What Is Already Known on this Topic:}

Various surgical approaches, such as anterior transthoracic, posterolateral, and posterior are in use for the treatment of giant spinal epidural tumors. Universal consensus on which surgical approach should be practiced has not yet been reached, nor as to which is the safest and least invasive, while still providing sufficient tumor exposure and allowing adequate instrumentation.

\section{What this Study Adds:}

An extensive posterolateral approach to giant spinal epidural tumors is a safe and effective one-step approach, allowing sufficient exposure for both tumor resection and spinal column reconstruction.

Authors' Contributions: Conception and design: JR, JŠ and JK; Acquisition, analysis and interpretation of data: JR and JŠ; Drafting the article JŠ; Revising it critically for important intellectual content: JR and JK; Approved final version of the manuscript: JR, JŠ and JK.

Conflict of Interest: The authors declare that they have no conflict of interest.

\section{References}

1. Wong DA, Fornasier VL, MacNab I. Spinal metastases: the obvious, the occult, and the impostors. Spine (Phila Pa 1976). 1990;15(1):1-4.

2. Prasad D, Schiff D. Malignant spinal-cord compression. Lancet Oncol. 2005;6(1):15-24.

3. Bach F, Larsen BH, Rohde K, Børgesen SE, Gjerris F, Bøge-Rasmussen T, et al. Metastatic spinal cord compression. Occurrence, symptoms, clinical presentations and prognosis in 398 patients with spinal cord compression. Acta Neurochir (Wien). 1990;107(1-2):37-43.

4. Posner JB. Back pain and epidural spinal cord compression. Med Clin North Am. 1987;71(2):185-205.

5. de Ruiter GC, Nogarede CO, Wolfs JF, Arts MP. Quality of life after different surgical procedures for the treatment of spinal metastases: results of a single-center prospective case series. Neurosurg Focus. 2017;42(1):E17.

6. Rong HT, Fan YS, Li SP, Zhang ZS, Liu H, Liu T, et al. Management of Dumbbell and Paraspinal Tumors of the Thoracic Spine Using a Single-stage Posterolateral Approach: Case Series. Orthop Surg. 2018;10(4):343-9.

7. Inamasu J, Guiot BH. Vascular injury and complication in neurosurgical spine surgery. Acta Neurochir (Wien). 2006;148(4):375-87.

8. Gezercan Y, Çavuş G, Ökten AI, Menekşe G, Çıkılı M, Adamhasan F, et al. Single-Stage Posterolateral Transpedicular Approach With 360-Degree Stabilization and
Vertebrectomy in Primary and Metastatic Tumors of the Spine. World Neurosurg. 2016;95:214-21.

9. Rustagi T, Mashaly H, Ganguly R, Akhter A, Mendel E. Transpedicular Vertebrectomy With Circumferential Spinal Cord Decompression and Reconstruction for Thoracic Spine Metastasis: A Consecutive Case Series. Spine (Phila Pa 1976). 2020;45(14):E820-8.

10. Wang JC, Boland P, Mitra N, Yamada Y, Lis E, Stubblefield $M$, et al. Single-stage posterolateral transpedicular approach for resection of epidural metastatic spine tumors involving the vertebral body with circumferential reconstruction: results in 140 patients. Invited submission from the Joint Section Meeting on Disorders of the Spine and Peripheral Nerves, March 2004. J Neurosurg Spine. 2004;1(3):287-98.

11. Joubert C, Adetchessi T, Peltier E, Graillon T, Dufour $\mathrm{H}$, Blondel B, et al. Corpectomy and Vertebral Body Reconstruction with Expandable Cage Placement and Osteosynthesis via the single stage Posterior Approach: a Retrospective Series of 34 Patients with Thoracic and Lumbar Spine Vertebral Body Tumors. World Neurosurg. 2015;84(5):1412-22.

12. Wilke HJ, Kemmerich V, Claes LE, Arand M. Combined anteroposterior spinal fixation provides superior stabilisation to a single anterior or posterior procedure. J Bone Joint Surg Br. 2001;83(4):609-17.

13. Zhao B, Xu J. Extensive posterolateral exposure and total removal of the giant extraforaminal dumbbell tumors of cervical spine: surgical technique in a series of 16 patients. Spine J. 2009;9(10):822-9.

14. Choi D, Fox Z, Albert T, Arts M, Balabaud L, Bunger C, et al. Rapid improvements in pain and quality of life are sustained after surgery for spinal metastases in a large prospective cohort. Br J Neurosurg. 2016;30(3):337-44.

15. Mohme M, Mende KC, Krätzig T, Plaetke R, Beseoglu $\mathrm{K}$, Hagedorn J, et al. Impact of spinal cord compression from intradural and epidural spinal tumors on perioperative symptoms-implications for surgical decision making. Neurosurg Rev. 2017;40(3):377-87.

16. Bellut D, Mutter UM, Sutter M, Eggspuehler A, Mannion AF, Porchet F. Back pain in patients with degenerative spine disease and intradural spinal tumor: what to treat? when to treat? Eur Spine J. 2014;23(4):821-9.

17. Quraishi NA, Rajabian A, Spencer A, Arealis G, Mehdian $\mathrm{H}$, Boszczyk BM, et al. Reoperation rates in the surgical treatment of spinal metastases. Spine J. 2015;15(3 Suppl):S37-43.

18. Amelot A, Balabaud L, Choi D, Fox Z, Crockard HA, Albert T, et al. Surgery for metastatic spine tumors in the elderly. Advanced age is not a contraindication to surgery! Spine J. 2017;17(6):759-67. 